Jakob Lager, Ole Hilberg, Anders Løkke and Elisabeth Bendstrup

Dept of Pulmonary Medicine, Aarhus University Hospital, Aarhus, Denmark.

Correspondence: J. Lager, Dept of Pulmonary Medicine, Aarhus University Hospital, Nørrebrogade 44, Aarhus, Denmark. E-mail: kabend@rm.dk

Received: April 012013 | Accepted: April 172013

Conflict of interest: Disclosures can be found alongside the online version of this article at www.err.ersjournals.com

Provenance: Submitted article, peer reviewed.

\title{
References
}

Schmitz S, Adams R, Walsh CD, et al. A mixed treatment comparison of the efficacy of anti-TNF agents in rheumatoid arthritis for methotrexate non-responders demonstrates differences between treatments: a Bayesian approach. Ann Rheum Dis 2012; 71: 225-230.

2 Pearce F, Johnson SR, Courtney P. Interstitial lung disease following certolizumab pegol. Rheumatology (Oxford) 2012; 51: 578-580.

Millar A, McKew J, Taggart A. Fatal fibrosing alveolitis with certolizumab. Rheumatology (Oxford) 2012; 51: 953-955. Perez-Alvarez R, Perez-de-Lis M, Diaz-Lagares C, et al. Interstitial lung disease induced or exacerbated by TNFtargeted therapies: analysis of 122 cases. Semin Arthritis Rheum 2011; 41: 256-264.

Hadjinicolaou AV, Nisar MK, Bhagat S, et al. Non-infectious pulmonary complications of newer biological agents for rheumatic diseases - a systematic literature review. Rheumatology (Oxford) 2011; 50: 2297-2305.

\section{Serious bronchopulmonary involvement due to chronic lymphocytic leukaemia}

\author{
To the Editor:
}

Chronic lymphocytic leukaemia (CLL) is the most common type of leukaemia, accounting for $40 \%$ of all cases in individuals $>65$ years of age. Thoracic complications of CLL can be classified into three groups: 1) infectious complications, which are by far the most frequent and are directly related to the severity of immunodeficiency secondary either to leukaemia or therapy; 2) pleural effusions that are either in CLL localisation or related to venous or lymphatic compression caused by a mass or lymph node, and 3) specific bronchopulmonary involvement secondary to lymphocytic infiltration.

Specific bronchopulmonary involvement due to chronic lymphocytic leukaemia (or pathologic leukaemic bronchopulmonary infiltration (LBPI)) is rare and there are few reports in the literature. We report the cases of six patients with CLL and bronchopulmonary leukaemic infiltrates who needed specific treatment due to the severity of respiratory symptoms.

The patients' characteristics are summarised in table S1 in the online supplementary material. All patients gave their written informed consent for inclusion in this report. The six patients were all males. Mean age was 70 years (range 64-74 years). Patient 1 was a current smoker (40 pack-years) and patients 4 and 6 were former smokers (10 PA). CLL had been diagnosed in all patients through a combination of blood hyperlymphocytosis, characteristic lymphocyte morphology and immunophenotyping carried out in the Haematology Department (Tours university Hospital, Tours, France), an average of 6.2 years previously (range 3-14 years). At diagnosis, none of the patients presented with respiratory symptoms or computed tomography (CT) scan abnormalities indicative of LBPI. Patients 1, 2, 4, 5 and 6 had a previous pulmonary history of infectious pneumonia. Only patient 1 had never received specific CLL treatment. All patients were considered to have been in CLL remission for a median of 6 months ( 1 month to 3 years) before the onset of respiratory symptoms.

At the time of onset of respiratory symptoms, four patients were at Binet stage C. Two patients did not have lymphocytosis and could be classified as small lymphocytic lymphoma. All patients had progressive lymphocytosis (four out of six patients) and/or nodal disease (two out of six patients with bilateral axillary and inguinal lymphadenopathies, and all six patients had mediastinal lymphadenopathies). Median lymphocytosis

This article has supplementary material available from err.ersjournals.com 

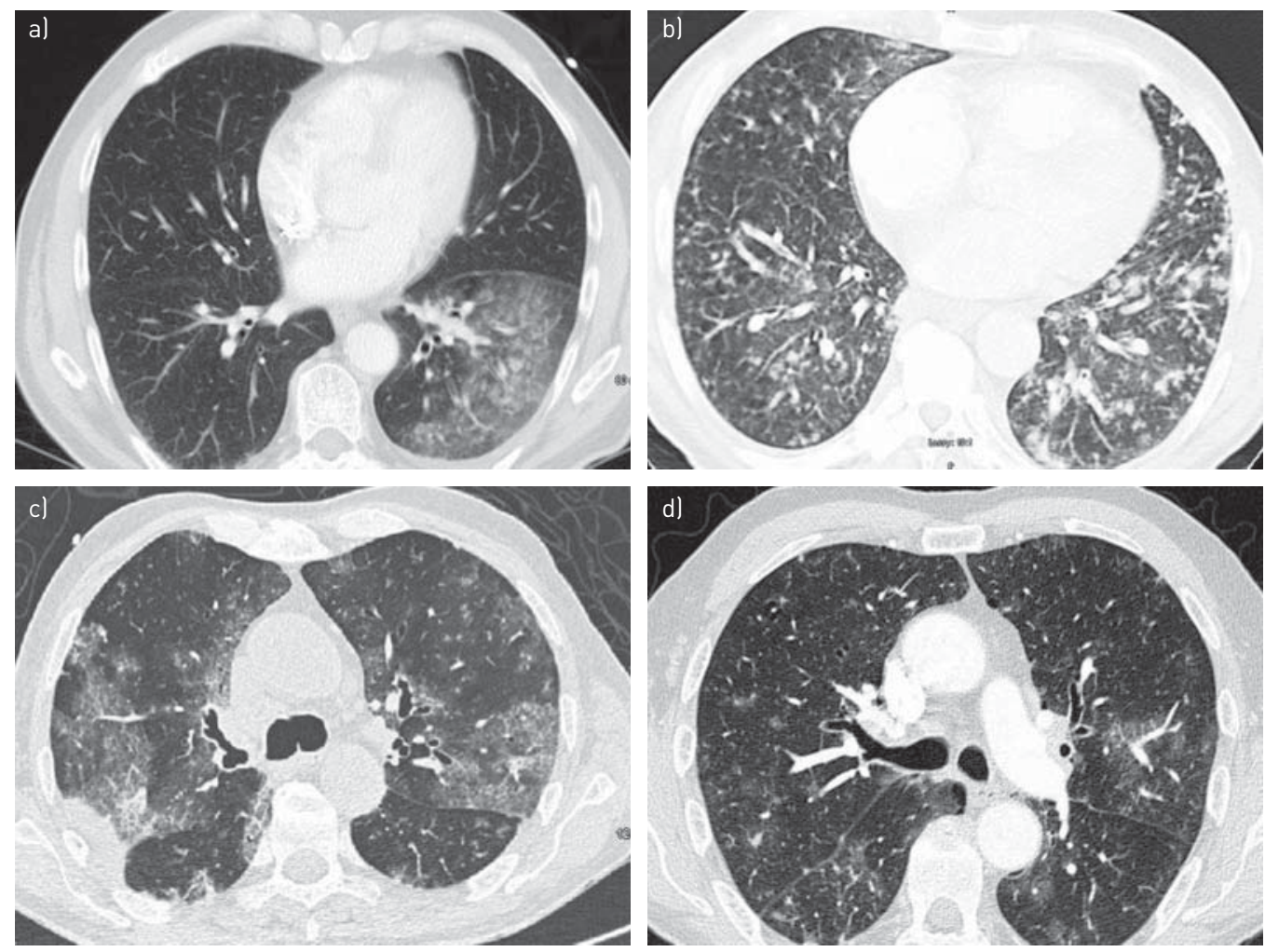

FIGURE 1 High-resolution computed tomography scans of patients with leukaemic bronchopulmonary infiltration showing the presence of: a) parenchymal condensation in the left lower lobe of patient 4 ; b) centrilobular micronodules with "tree-in-bud" pattern in patient 1; c) parenchymal condensation, ground-glass opacities and proximal bronchiectasis in patient 5; and d) centrilobular micronodules and perivascular ground-glass opacities in patient 6 .

was $27.2 \times 10^{9}$ cells $\cdot \mathrm{L}^{-1}\left(0.7-127 \times 10^{9}\right.$ cells $\left.\cdot \mathrm{L}^{-1}\right)$. Patient 2 presented with skin involvement and patient 5 with sinus involvement due to CLL and confirmed by biopsies. All patients had a 1-month history of cough, fever and dyspnoea despite appropriate polyantibiotic therapy. Physical examination revealed bilateral crackles in all patients. No patient had received corticosteroid therapy. Patients presented with hypoxaemia on blood gas with a median arterial oxygen tension of $59 \mathrm{mmHg}$ in ambient air $(53-61 \mathrm{mmHg})$.

A thoracic CT scan revealed multiple bilateral mediastinal lymphadenopathy $(n=6)$, centrilobular micronodules with a "tree-in-bud" pattern $(n=5)$, rapid development of bronchectasis within 4 months $(n=1)$, and ground-glass opacities with centrilobular distribution $(n=6)$ or homogeneous parenchymal consolidation $(\mathrm{n}=4)$ (fig. 1).

Results of repeated bacteriological (on bronchoalveolar lavage and blood samples), mycobacteriological, virological and mycological tests were negative in five patients. Patient 5 was chronically colonised with Stenotrophomonas maltophilia.

Bronchoalveolar lavage fluid (BALF) revealed hypercellularity $565000 \mathrm{cells} \cdot \mathrm{mL}^{-1}(171000$ to 15000000 cells $\left.\cdot \mathrm{mL}^{-1}\right)$. Median lymphocytic alveolitis was $52 \%(2-84 \%)$, with CD8 alveolitis in two patients. BALF of the six patients showed no contamination with erythrocytes. LBPI was confirmed by immunohistochemical examination from transbronchial biopsy (patients 3 and 4), bronchial biopsy (patients 5 and 6) and by flow cytometry from BALF (patients 1, 2, 3 and 4). Histological examination of bronchial and transbronchial biopsies showed a lymphocytic chorion infiltrate sometimes grouped in nodules, confirmed by immunohistochemical examination to be B-CLL elements (fig. 2).

Due to LBPI severity, combination chemotherapy for CLL had been proposed for all patients, leading to clinical and radiological improvement in patients 1,2, 4 and 6. Patient 3 declined treatment and died 2 months after the diagnosis of LBPI. Cause of death was respiratory failure due to CLL bronchopulmonary involvement. Patient 5 died 1 month after the diagnosis of LBPI. Cause of death was respiratory failure due to CLL bronchopulmonary involvement with probable infection with S. maltophilia.

We report the cases of six patients with specific and symptomatic leukaemic bronchopulmonary infiltration. Respiratory symptoms were predominant in all patients and required specific treatment for CLL. 

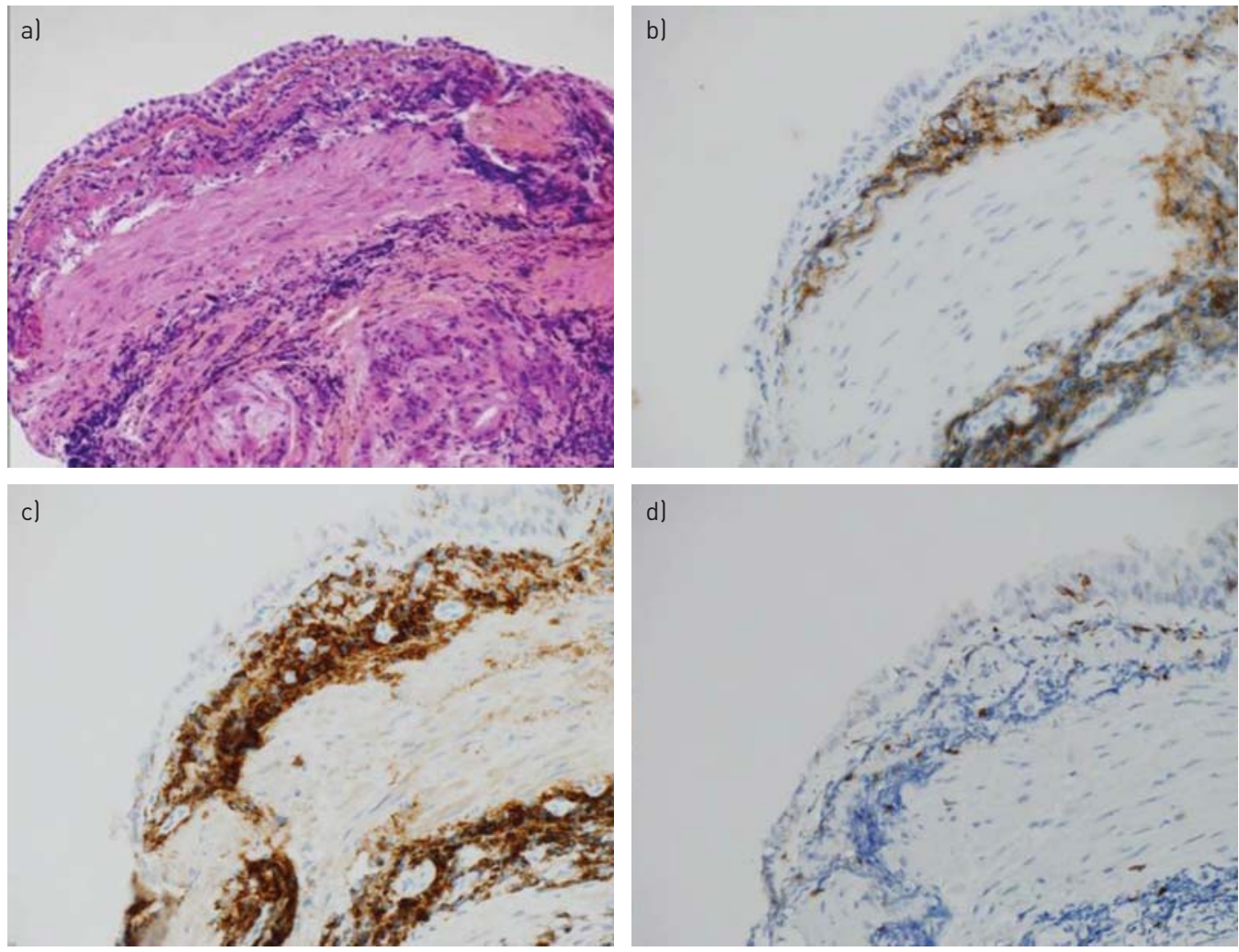

FIGURE 2 Bronchial biopsy from patient 5 (a; Haematoxylin-Eosin-Safran stain and $\times 10$ growth). CD3 immunostaining $(\mathrm{d}$; original magnification $\times 40$ ) highlights the presence of rare and scattered T-cells, while the abundance of reactive small B-cells is emphasised by immunostaining for CD20 (b; original magnification $\times 40)$ and CD5 (c; original magnification $\times 40)$.

As usually described in LBPI, our patients had a nonspecific clinical presentation involving a history of several weeks of cough, progressive dyspnoea and low-grade fever. According to AHMED et al. [1], respiratory symptoms of LBPI are rare, accounting for only $2.1 \%$ of pulmonary complications in CLL.

The diagnosis of LBPI was based on a battery of tests (CT imaging, BALF, immunophenotyping, etc.). Infectious causes were firmly ruled out in all patients. Some authors report that there is no correlation between pulmonary leukaemic infiltrates and the peripheral blood absolute lymphocyte count [2]. However, in the study by Hill et al. [3], there was a trend towards a higher absolute lymphocyte count in cases of leukaemic pulmonary infiltrates. The radiological appearance of pulmonary leukaemic infiltrates has been described as nonspecific [2], but mosaic perfusion, expiratory air-trapping and centrilobular nodules in a tree-in-bud pattern suggest bronchiolar involvement [4-6]. Central bronchiectasis, sometimes seen in CLL patients, can be the result of repeated infections or of bronchial infiltration by lymphocytes $[7,8]$. Bronchoalveolar lavage is important to exclude other diagnoses in these immunocompromised patients. It can reveal LBPI, showing lymphocytic alveolitis with a majority of small leukaemic B lymphocytes in immunophenotyping by flow cytometry. However, bronchoalveolar lavage alone is not sufficient to detect LBPI [3, 9, 10]. As in two of our patients, RolLA et al. [11] reported CD8 alveolitis without any B leukaemic cells in the bronchoalveolar lavage of 10 patients with CLL.

The diagnosis of LBPI was primarily histological in four of our patients. Autopsy studies of patients with CLL demonstrate lung involvement in up to $40 \%$ of patients, but these patients are usually asymptomatic [12]. In general, pulmonary biopsies reveal a dense B-CLL infiltrate, usually with a peribronchial and perivascular distribution $[2,13]$. Cases of endobronchial CLL causing bronchial obstruction and atelectasis have also been reported $[7,8]$. A granulomatous reaction in CLL, sometimes necrotic, has previously been observed without any evidence of infection. Moreover, in a review of 49 lung biopsies from 38 patients with CLL or small lymphocytic lymphoma and pulmonary opacities on CT scan, HiLL et al. [3] found pathologic leukaemic pulmonary infiltration in seven $(18.4 \%)$ out of 38 patients. A neutrophilic inflammation was only found in two cases out of 21 samples analysed. The authors concluded that specific leukaemic infiltration by CLL is not a nonspecific "passenger effect" secondary to increased permeability due to ongoing inflammation and host response, but does in fact indicate real extranodal tissue involvement [3]. 
Our six patients were severely handicapped by the LBPI; two patients died as a direct result. The respiratory symptoms and CT opacities of the other four patients improved after antineoplastic therapy. In the study by HILl et al. [3], the clinical symptoms of three out of four patients treated with chemotherapy for LBPI improved [7].

In conclusion, the onset of respiratory symptoms in a patient with CLL should suggest the diagnosis of LBPI irrespective of the extent of peripheral blood lymphocyte count, and indicates the need for specific treatment.

\section{0} @ERSpublications

Pathologic LBPI is rare but could require specific treatment due to the severity of respiratory symptoms http://ow.ly/mNoer

Delphine Carmier ${ }^{1}$, Catherine Dartigeas ${ }^{2}$, Julie Mankikian ${ }^{1}$, Cecilla Rousselot-Denis ${ }^{3}$, Severine Lissandre ${ }^{2}$, Patrice Diot ${ }^{1,4}$ and Sylvain Marchand-Adam ${ }^{1,4}$

${ }^{1}$ CHRU Tours, Service de pneumologie et explorations fonctionnelles respiratoires, Tours, ${ }^{2}$ CHRU Tours, Service d'hématologie thérapie cellulaire, Tours, ${ }^{3} \mathrm{CHRU}$ Tours, Service d'anatomopathologie, Tours, and ${ }^{4}$ Université FrançoisRabelais de Tours, Inserm U1100, Faculté de médecine, Tours, France.

Correspondence: D. Carmier, CHRU Tours, Service de pneumologie et explorations fonctionnelles respiratoires, Tours, France. E-mail: delphine_carmier@yahoo.fr

Received: Dec 292012 | Accepted: Feb 172013

Conflict of interest: None declared.

Provenance: Submitted, peer reviewed.

\section{References}

1 Ahmed S, Siddiqui AK, Rossof L, et al. Pulmonary complications in chronic lymphocytic leukemia. Cancer 2003; 98: 1912-1917.

2 Berkman N, Polliack A, Breuer R, et al. Pulmonary involvement as the major manifestation of chronic lymphocytic leukemia. Leuk Lymphoma 1992; 8: 495-499.

3 Hill B, Weil A, Kalaycio M, et al. Pulmonary involvement by chronic lymphocytic leukemia/small lymphocytic lymphoma is a specific pathologic finding independent of inflammatory infiltration. Leuk Lymphoma 2012; 53: 589-595.

4 Trisolini R, Lazzari Agli L, Poletti V. Bronchiolocentric pulmonary involvement due to chronic lymphocytic leukemia. Haematologica 2000; 85: 1097.

5 Fretz G, Krause M, Thurnheer R. Chronic lymphocytic leukemia, dyspnoea and "tree-in-bud" sign on chest CT scan. BMJ Case Rep 2009; 2009: pii bcr03.2009.1672.

6 Moore W, Baram D, Hu Y. Pulmonary infiltration from chronic lymphocytic leukemia. J Thorac Imaging 2006; 21: $172-175$

7 Chemoff A, Rymuza J, Lipmann ML. Endobronchial lymphocytic infiltration: unusual manifestation of chronic lymphocytic leukemia. Am J Med 1984; 77: 755-759.

8 Desjardins A, Ostiguy G, Cousineau S, et al. Recurrent localized pneumonia due to bronchial infiltration in patient with chronic lymphocytic leukemia. Thorax 1990; 45: 570.

9 Cazzadori A, Di Perri G, Todeschini G, et al. Transbronchial biopsy in the diagnosis of the pulmonary infiltrates in immunocompromised patients. Chest 1995; 107: 101-106.

10 Mulabecirovic A, Gaulhofer P, Auner HW, et al. Pulmonary infiltrates in patients with haematologic malignancies: transbronchial lung biopsy increases the diagnostic yield with respect to neoplastic infiltrates and toxic pneumonitis. Ann haematol 2004; 83: 420-422.

11 Rolla G, Bucca C, Chiampo F, et al. Respiratory symptoms, lung function tests, airways responsiveness, and bronchoalveolar lymphocytes subsets in B-chronic lymphocytic leukemia. Lung 1993; 171: $265-275$.

12 Barcos M, Lane W, Gomez GA, et al. An autopsy study of 1206 acute and chronic leukemias (1958 to 1982). Cancer 1987; 60: 827-837.

13 Palosaari D, Colby T. Bronchiolocentric chronic lymphocytic leukemia. Cancer 1986; 58: 1695-1698. 